\title{
Interprofessional Education: The CA-IPERA Model for Learning
}

\author{
Nassrine Noureddine ${ }^{1^{\star}}$, Darla K. Hagge ${ }^{2}$, Debra Brady ${ }^{3}$ and William Ofstad ${ }^{3}$ \\ ${ }^{1}$ Department of Nursing, California State University Sacramento, USA \\ ${ }^{2}$ Department of Speech-Language Pathology \& Audiology, California State University Sacramento, USA \\ ${ }^{3}$ Department of Nursing, California State University Sacramento, USA
}

\section{Publication History:}

Received: June 13, 2016

Accepted: September 05, 2016

Published: September 07, 2016 health outcomes. As a result, interprofessional education is quickly becoming the accreditation standard for multiple healthcare disciplines including medicine, nursing, pharmacy, physical therapy and speechlanguage pathology. In addition to developing curriculum that is highly engaging while also preparing students to address the challenges of providing safe and effective care to increasingly ill patients, health care educators must also design, refine, and embed interprofessional education activities into an often impacted program. This article will provide a brief background of interprofessional education, current accreditation expectations across healthcare disciplines and discuss the development of the CaliforniaInterprofessional Education Research Academy Model

\section{Interprofessional Education}

\section{Background}

Health care professionals are expected to be lifelong learners, starting as students in an educational program and continuing as members of a multidisciplinary healthcare team. Throughout this learning continuum, healthcare students and workers may learn about, from and with each other during formal or spontaneous interactions. This is referred to as Interprofessional Learning, which is an inclusionary philosophy that encompasses both interprofessional education and interprofessional practice [1,2].

Interprofessional Education (IPE) ensues when students from two or more healthcare disciplines have the opportunity to "learn about, from, and with" one another [3]. IPE provides students with significant and challenging learning activities that are designed to develop teamwork, ethical practice, an understanding of professional roles, and communication skills that enhance interdisciplinary collaboration. IPE also contributes to breaking out of individual programmatic silos, which is a long-held convention in higher education. Hence, IPE prepares healthcare professionals who have been educated and trained to collaborate effectively in multidisciplinary teams to provide improved services to patients that result in stronger health outcomes and improved safety [4].

Although an exhaustive analysis of terminology is beyond the scope of this paper, it is important to include a brief discussion of the terms multidisciplinary and interprofessional, which are often used interchangeably. There are subtle but significant differences between these two labels [5]. The term, multidisciplinary, suggests the addition of two or more disciplines providing patient care. In contrast, interprofessional, indicates a purposeful, integrated, collaborative approach to patient care. According to the WHO [3], it is interprofessional practice that requires the combined knowledge and skills from multiple disciplines to provide healthcare that supports patient safety and improved outcomes.

In 2002, the Institute of Medicine (IOM) released its report on the health professions education summit in which the importance to reform and restructure clinical education was stressed to be consistent with the needs of the $21^{\text {st }}$ century. The report's authors strongly recommend that all health professions be educated to deliver patient centered care as members of an interprofessional team emphasizing evidence based practice, quality improvement and informatics to improve the quality and safety of health care.

\section{IPE seminal reports}

Several seminal reports have been published over the last 10 years exploring and promoting the need for IPE (Table 1). In 2015, the Institute of Medicine (IOM) released a clarion call for professionals, researchers, and educators to measure the impact of IPE on direct patient care. The current targeted areas of research include aligning educational practices with healthcare services, developing a framework to measure the impact of IPE on health care services, increasing the efficacy of evidence regarding IPE, and documenting the impact of IPE on collaborative communication and teamwork [6].

\begin{tabular}{|c|c|c|}
\hline Organization & Year & Name of Seminal Report \\
\hline $\begin{array}{l}\text { Institute of } \\
\text { Medicine (IOM) }\end{array}$ & 2015 & $\begin{array}{l}\text { Measuring the Impact of Interprofessional } \\
\text { Education on Collaborative Practice and Patient } \\
\text { Outcomes } \\
\text { Interprofessional education for collaboration: } \\
\text { Learning how to improve health from } \\
\text { interprofessional models across the continuum of } \\
\text { education to practice: Workshop summary } \\
\text { Committee on the Health Professions Education } \\
\text { Summit. Health Professions Education: A Bridge } \\
\text { to Quality. }\end{array}$ \\
\hline $\begin{array}{l}\text { Interprofessional } \\
\text { Education } \\
\text { Collaborative } \\
\text { (IPEC) }\end{array}$ & $\begin{array}{l}2016 \\
2011\end{array}$ & $\begin{array}{l}\text { Core Competencies for Interprofessional } \\
\text { Collaborative Practice: } 2016 \text { Update } \\
\text { Core Competencies for Interprofessional } \\
\text { Collaborative Practice }\end{array}$ \\
\hline $\begin{array}{l}\text { World Health } \\
\text { Organization } \\
(\mathrm{WHO})\end{array}$ & 2010 & $\begin{array}{l}\text { Framework for Action on Interprofessional } \\
\text { Education and Collaborative Practice }\end{array}$ \\
\hline
\end{tabular}

"Corresponding Author: Dr. Nassrine Noureddine, Department of Nursing, California State University Sacramento, USA; E-mail: noureddinen@csus.edu

Citation: Noureddine N, Hagge DK, Brady D, Ofstad W (2016) Interprofessional Education: The CA-IPERA Model for Learning. Int J Nurs Clin Pract 3: 197. doi: http://dx.doi.org/10.15344/2394-4978/2016/197

Copyright: () 2016 Noureddine et al. This is an open-access article distributed under the terms of the Creative Commons Attribution License, which permits unrestricted use, distribution, and reproduction in any medium, provided the original author and source are credited. 
Citation: Noureddine N, Hagge DK, Brady D, Ofstad W (2016) Interprofessional Education: The CA-IPERA Model for Learning. Int J Nurs Clin Pract 3: 197. doi: http://dx.doi.org/10.15344/2394-4978/2016/197

Page 2 of 4

\section{Interprofessional Education Collaborative (IPEC)}

Several seminal reports have been published over the last 10 years exploring and promoting the need for IPE (Table 1). In 2015, the Institute of Medicine (IOM) released a clarion call for professionals, The IPEC was established in 2009 by the leaders of six national healthcare education associations to "prepare future professionals for enhanced team based care and improved health outcomes" [7]. These multidisciplinary health professional education organizations sought to develop innovative curricula across disciplines and prepare students to engage in interprofessional practice. Additional health and health related organizations have joined to support the mission of IPEC including the American Speech-Language-Hearing Association, American Physical Therapy Association, and the Association of Schools of Allied Health Professions (Table 2). Currently, IPEC (2015) hosts biannual conferences to promote IPE and offers funding resources designed to support the development of interprofessional education and training.

\section{Four Domains of IPE Competency}

The IPEC has developed four domains of competency for IPE and supports the development of student skills in: (a) Values and ethics for interprofessional practice, (b) Roles and responsibilities, (c) Interprofessional communication, and (d) Teams and teamwork. Each domain includes a broad collection of knowledge, skills, attitudes and values to demonstrate proficiency in the four areas (Figure 1). The IPEC offers a comprehensive, online report detailing multiple goals within each domain [8]. In addition, the National Center for Interprofessional Practice and Education [7] is an invaluable resource for educators and professionals who are interested in IPE curriculum, research, and assessment tools. Many of the materials are available online and are free-of-charge.

\section{Clinical and Educational Benefits of IPE}

The clinical benefits of interprofessional education are significant, positively impacting the lives of those who provide, and ultimately

\begin{tabular}{|l|l|l|}
\hline \multicolumn{2}{|l|}{ Six Founding Organizations } & \multicolumn{2}{|l|}{ Supporting Organizations } \\
\hline $\begin{array}{l}\text { American Association of the Colleges of Nursing } \\
\text { (AACN) }\end{array}$ & $\begin{array}{l}\text { Academic Consortium for Complementary \& } \\
\text { Alternative Health Care (ACCAHC) }\end{array}$ & $\begin{array}{l}\text { American Speech-Language-Hearing } \\
\text { Association (ASHA) }\end{array}$ \\
\hline $\begin{array}{l}\text { American Association of Colleges of Osteopathic } \\
\text { Medication (AACOM) }\end{array}$ & $\begin{array}{l}\text { American Association of Colleges of Podiatric } \\
\text { Medicine (AACPM) }\end{array}$ & $\begin{array}{l}\text { Association of Schools and Colleges of } \\
\text { Optometry (ASCO) }\end{array}$ \\
\hline $\begin{array}{l}\text { American Association of Colleges of Pharmacy } \\
\text { (AACP) }\end{array}$ & $\begin{array}{l}\text { American Council of Academic Physical } \\
\text { Therapy (ACAPT) }\end{array}$ & $\begin{array}{l}\text { Association of Schools of Allied Health } \\
\text { Professions (ASAHP) }\end{array}$ \\
\hline American Dental Education Association (ADEA) & American Physical Therapy Association (APTA) & Council on Social Work Education (CSWE) \\
\hline $\begin{array}{l}\text { Association of American Medical Colleges } \\
\text { (AAMC) }\end{array}$ & $\begin{array}{l}\text { American Occupational Therapy Association } \\
\text { (AOTA) }\end{array}$ & $\begin{array}{l}\text { Physician Assistant Education Association } \\
\text { (PAEA) }\end{array}$ \\
\hline $\begin{array}{l}\text { American Association of Schools and Programs } \\
\text { of Public Health (ASPPH) }\end{array}$ & American Psychological Association (APA) & Society of Simulation in Healthcare (SSIH) \\
\hline $\begin{array}{l}\text { Table 2: Interprofessional Education Collaborative Founding and Supporting Members. } \\
\text { Rote: Adapted from The Interprofessional Education Collaborative, IPEC News \& Events. }\end{array}$ \\
\begin{tabular}{l} 
Retrieved from https://ipecollaborative.org/ \\
\hline
\end{tabular}
\end{tabular}

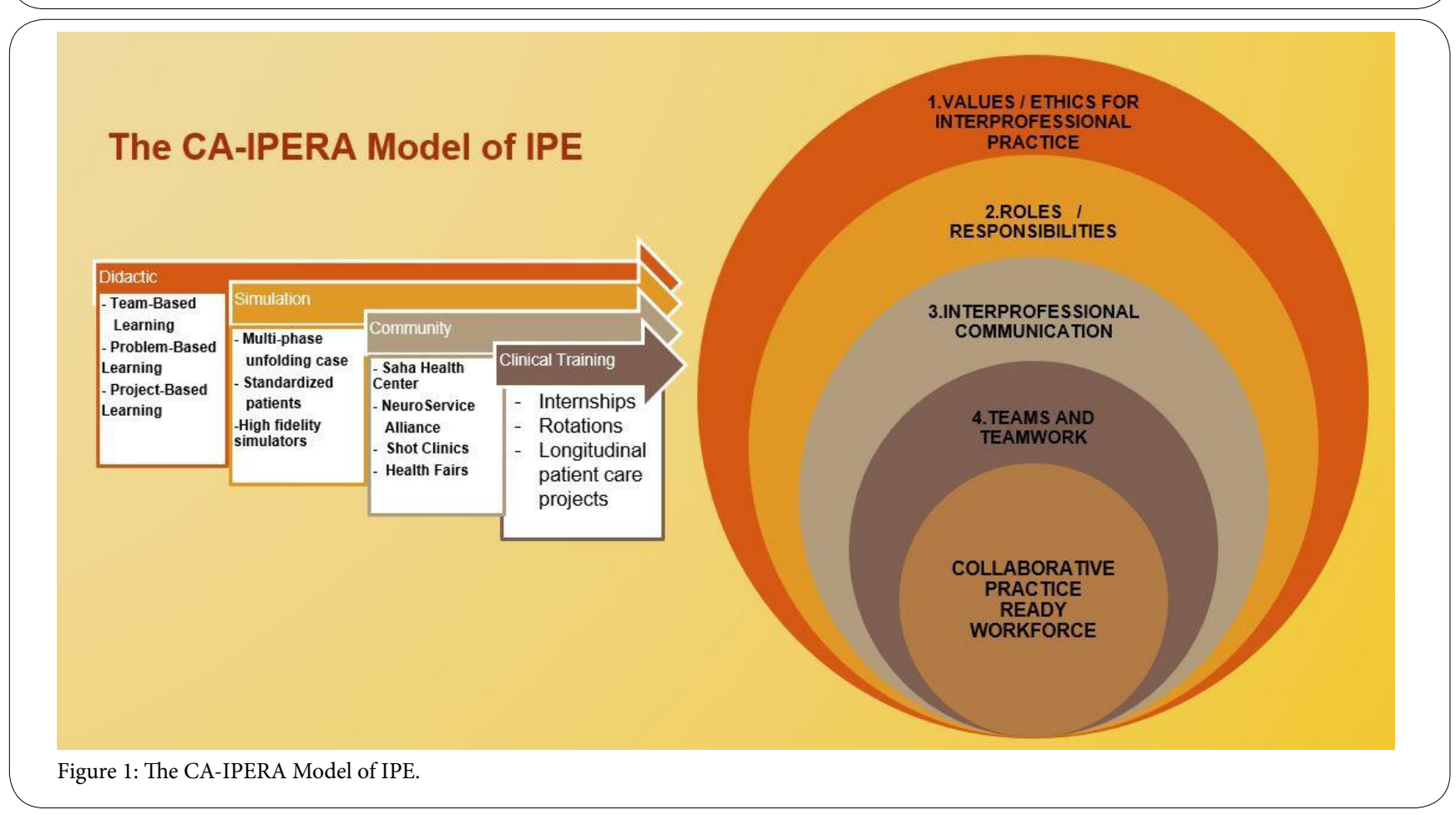


those who receive interprofessional health care services. From the health care providers' perspective, benefits include improved employee morale, practices and productivity. Patients and their significant others benefit from greater access to health care services, enhanced patient outcomes, and improved patient safety [3]. Further evidence is needed, however, to fully understand the connectivity between interprofessional education and improved patient safety and other outcomes [6].

Healthcare students learn core knowledge, skills, attitudes and values and are asked to quickly apply learning to a clinical or functional setting. Their ability to move from receiving direct instruction to clinical practice is facilitated through supervised interprofessional training in simulation, experiential opportunities, and co-curricular settings.

\section{Clinical Benefits of IPE}

By design, IPE provides healthcare students with real world experiences, cross disciplinary exposure, and interprofessional input. These factors converge and provide multiple educational benefits. The carefully created scaffolded learning experiences that are designed to achieve IPEC goals positively impact clinical outcomes in the following manner. First, IPE breaks the traditional silos in healthcare education resulting in a greater understanding of the different roles and responsibilities of each discipline. This leads to enhanced experience with communicating within and across disciplines, hence improving communication between the various professions in the professional

setting. Second, IPE develops the skill of working in teams, and this transferable skill positively impacts the clinical environment by creating a collaborative healthcare workforce. Finally, IPE enhances Interprofessional Practice (IPP) which leads to a reduction in clinical errors, improvement in patient safety, and ultimately positive health outcomes [3].

\section{Limitations of IPE}

Despite all previously stated benefits of IPE, there are limitations. The literature reflects multiple limitations at the organization, department and individual levels [9]. Specific limitations or barriers experienced by the authors include time-constraints for planning and building IPE teams and activities, scheduling logistics for multidisciplinary faculty and students, as well as facility limitations in terms of room size, furniture, and equipment.

\section{Accreditation Expectations for IPE}

The accreditation landscape supporting interprofessional education in the United States is rapidly evolving. Most health professional education accreditors and academic associations now emphasize IPE and expect schools and colleges to develop interprofessional curriculum and assess learning of interpersonal communication, ethical practice, roles, and teamwork. Examples of accreditation standards and national initiatives emphasizing IPE are provided in Table 3. Understanding accreditation across the health disciplines can be key to motivate and maintaining partnerships with administrative support, shared resources, and faculty development.

\section{Current Focus of IPE Research}

In the 2015 IOM report, Measuring the Impact of Interprofessional Education on Collaborative Practice and Patient Outcomes, the authors explore the evidence linking interprofessional education to patient and health system outcomes and suggests approaches to strengthening this evidence base. The new report indicates that patients are essential partners in health promotion and health care delivery. In addition, health care teams are seen as comprised of multiple health professions.

Many attempts have been made in the past decade to incorporate interprofessional education in health care professions education. This time, however, the authors recommend in-depth and widespread adoption of interprofessional education while aligning interprofessional education with collaborative care. According to the report, most of the IPE literature reviewed focused on the impact of IPE on learners' knowledge, skills, and attitudes. There is, however, a need to focus on the link between IPE and performance in practice, including the impact of IPE on patient and population health and health care delivery system outcomes. The authors call for the adoption of a new model encompassing both education and health as complementary factors rather than components that are measured in isolation. Finally, the authors calls on health professionals around the globe to learn to work together to extend the wellbeing of individuals globally.

\section{CA-IPERA Model for Integrated IPE Experiences}

Interprofessional education begins with faculty who are willing to collaborate across disciplines and explore new approaches of instruction and student learning. In the state of California of the United States, faculty members from multiple institutions representing the fields of medicine, nursing, pharmacy and speech-language pathology formed a team to collaborate on curriculum development and research while mentoring students interested in IPE scholarship and delivery. This 5-year alliance resulted in the development of a robust interprofessional curriculum that is focused on preparing a successful, collaborative, practice-ready workforce and is referred to as the CA-IPERA Model for Integrated IPE Experiences.

The CA-IPERA Model provides IPE activities for two or more disciplines using four specific modes of interprofessional learning experiences: (a) didactic, (b) simulation, (c) community and (d) clinical training. Didactic learning purposefully integrates multiple pedagogies. Students enjoy meeting and learning together about one another in a variety of didactic experiences. Teaching strategies include content delivery via direct instruction, use of multimedia or other teaching modalities, team-based learning as well as the use of

\begin{tabular}{|l|l|}
\hline Discipline & Accreditation Standards \\
\hline Pharmacy & ACPE 2016, Standard 11 \\
\hline Medicine & $\begin{array}{l}\text { LCME 2015, Standard 7.9 } \\
\text { AOA 2014, Standard 6.4 }\end{array}$ \\
\hline Nursing & $\begin{array}{l}\text { ACEN 2013, Standard 4.6 } \\
\text { AACN 2008, Essential VI }\end{array}$ \\
\hline Dentistry & CODA 2014, Educational Environment \\
\hline $\begin{array}{l}\text { Speech-Language } \\
\text { Pathology \& Audiology }\end{array}$ & CAA, 2016, Standards \\
\hline $\begin{array}{l}\text { Physical Therapy } \\
\text { CAPTE, 2016, Standards and Required } \\
\text { Elements }\end{array}$ \\
\hline $\begin{array}{l}\text { Social Work } \\
\text { Accreditation Board }\end{array}$ & CSWA, 2008, Educational policy M2.2. \\
\hline
\end{tabular}

Table 3: U.S. Accreditation Standards by Discipline. 
clinical case-based and problem-based scenarios. Interprofessional simulation scenarios were created to address one or more of the four IPEC competencies. In terms of community-based interprofessional clinical practice, undergraduate and graduate students from multiple healthcare disciplines are offered the opportunity to participate in hands-on, experiential learning. Through multiple community clinics, health fairs and other events, students experience interprofessional training while also serving the needs of the community. Finally, clinical training is currently being developed with the resultant goal of assigning interprofessional student teams together to formal clinical internship rotations.

\section{CA-IPERA Model for Integrated IPE Experiences}

Based on qualitative and quantitative measures, the CA-IPERA model demonstrates positive learning outcomes for healthcare students [10-12]. These interprofessional activities were standardized using multiple steps. Initially, each newly designed interprofessional training activity was piloted, reviewed, revised, and piloted again the following semester. Thereafter, instructors met to debrief and review the outcomes for possible modifications following each interprofessional experience. Simulation scenarios were also betatested, with one publication [12] and two other manuscripts that are in-progress.

Students learn interprofessional collaboration by observing faculty who model interprofessional collaboration. This further strengthens the learning for students. In addition, the benefits of applying this model to the curriculum are not only limited to student achievement but also apply to faculty productivity [13-15]. The synergy of collaboration and teamwork experienced by faculty involved in CA-IPERA resulted in an abundance of scholarly opportunities. Consequently, faculty are also positively impacted by learning about and from each other, sharing expertise, and helping one another grow in his/her professional roles [16-17].

\section{Conclusion}

IPE enables educators to implement nationally and internationally recommended best practices in health care education and is not difficult to get started. IPE begins with a conversation between two or more cross-disciplinary professionals regarding relevant and authentic issues that are currently being experienced in the clinical setting. Once an issue is identified and considered, it can be re-created for a select cadre of multidisciplinary students to learn and experience. Afterwards, the experience can be evaluated, modified, expanded, and repeated each semester. The potential for significant and measurable interprofessional learning outcomes, improved interdisciplinary teamwork, and enhanced patient safety is worth taking the first step towards integrating IPE into the curriculum.

\section{Competing Interests}

The author (s) declare that they have no competing interestes.

\section{References}

1. Centre for the Advancement of Interprofessional Education (CAIPE; 2002). The definition and principles of interprofessional education.

2. Freeth DS, Hammick M, Reeves S, Koppel I, et al. (2008) Effective interprofessional education: Development, delivery, and evaluation. John Wiley \& Sons.

3. World Health Organization (2010) Framework for Action on Interprofessiona Education \& Collaborative Practice.
4. IOM (2003) Health professions education: A bridge to quality. Washington, DC: The National Academies Press.

5. Page RL, Hume AL, Trujillo JM, Leader WG, Varden O, et al. (2012) Interprofessional education: Principles and application a framework for clinical pharmacy. Pharmacotherapy: The J Human Pharmacology Drug Therapy 29: 145-164.

6. IOM (2015) Measuring the impact of interprofessional education on collaborative practice and patient outcomes. Washington DC: The National Academies Press.

7. National Center for Interprofessional Practice and Education (2015). Informing, Connecting Engaging, Advancing.

8. Interprofessional Education Collaborative Expert Panel (2011) Core competencies for interprofessional collaborative practice: Report of an expert panel. Washington.

9. West C, Graham L, Palmer RT, Miller MF, Thayer EK, et al. (2016) Implementation of interprofessional education (IPE) in 16 US medical schools: Common practices, barriers and facilitators. J Interprof Edu Prac 4: $41-49$.

10. Noureddine N, Hagge D, Brady D (2015) Breaking the silos between nursing \& speech-language pathology students through interprofessional simulation training. Poster presentation at the American Speech-Language Hearing Association National Annual Convention Colorado.

11. Noureddine N, Hagge D, Brady D, Ofstad W (2015) Promoting student resiliency through Interprofessional Education Collaboration. A podium presentation at the Sigma Theta Tau International Scientific Proposal Symposium, in Las Vegas, Nevada.

12. Noureddine N, Hagge D, Brady D (2014) Middle Cerebral Artery CVA Speech Language Pathology. In California Simulation Alliance.

13. Grant $R$, Finocchio $L$ (1995) Interdisciplinary collaborative teams in primary care: A model curriculum and resource guide. Pew Health Professions Commission.

14. Interprofessional Education Collaborative (2015) What is Interprofessional Education?

15. Interprofessional Education Collaborative Expert Panel (2016) Core competencies for interprofessional collaborative practice: 2016 Update. Washington DC: Interprofessional Education Collaborative.

16. IOM (2013) Interprofessional education for collaboration: Learning how to improve health from interprofessional models across the continuum of education to practice: Workshop summary. Washington DC: The National Academies Press.

17. IOM (2002) The future of the public's health in the 21st century. Washington, DC: The National Academies Press. 